\title{
Los origenes del trotskismo argentino: de los años 30 al surgimiento del peronismo. Elaboraciones teórico-políticas y vinculos con la clase obrera
}

\author{
Alicia Rojo \\ UBA
}

El trotskismo es una corriente de izquierda presente en la Argentina desde fines de la década de 1920, actuando en múltiples ámbitos de la vida política nacional. Los primeros trotskistas procuraron insertarse en la clase obrera, establecieron lazos con la intelectualidad, trataron de vincularse a la corriente internacional a la que pertenecian y delinearon posiciones teóricas y políticas alrededor del análisis de la estructura económica, los fenómenos políticos nacionales e internacionales y particularmente aquellos que involucraron a los trabajadores.

La permanencia de esta corriente en nuestro país es un hecho incontestable $\mathrm{y}$, sin embargo, ha estado prácticamente ausente en la producción historiográfica. Ambos elementos, el peso relativo de esta corriente política y la escasa investigación sobre su historia, fundamentan la relevancia de nuestro objetivo: indagar en los orígenes del trotskismo argentino y en su ubicación frente al fenómeno político más importante que atravesó a la clase obrera nacional, el peronismo. ${ }^{1}$

De conjunto, nuestra investigación apunta a demostrar que los trotskistas, lejos de conformar grupos ajenos a la realidad nacional, han ejercido una notable influencia en todos los ámbitos de la vida política, sindical e incluso intelectual, ${ }^{2}$ soldando duraderos vínculos fundamen-

\footnotetext{
1.Las líneas de trabajo que presentamos aquí guían un programa de investigación que se encuentra en desarrollo y que se propone construir una historia del trotskismo en nuestro país. Hemos dado algunos pasos en esta propuesta expresados en una serie de trabajos realizados en el marco del Centro de Estudios, Investigaciones y Publicaciones "León Trotsky".

2. No está de más señalar la influencia que muchas de las elaboraciones de intelectuales de origen trotskista han ejercido entre referentes del ámbito académico, sea esta influencia reconocida o no. La reciente reedición de la obra de Milcíades Peña, un reconocido militante trotskista, y su reivindicación como exponente de una concepción marxista de la historia argentina, es un buen ejemplo.
} 
talmente con sectores de trabajadores, los cuales emergen en muchos de los fenómenos más significativos de la lucha de clases nacional.

Nos interesa destacar aquí los aportes realizados por los primeros trotskistas, así como los obstáculos que encontraron para constituirse en una alternativa política para el movimiento obrero en esta etapa; procurando establecer el balance entre las condiciones objetivas en que se dio su desarrollo y las potencialidades y los limites con que las enfrentaron. En este trabajo nos concentraremos en la década del 30 y los primeros años 40, haciendo un recorrido de la bibliografia existente sobre el tema, diseñando los principales núcleos problemáticos que se desprenden de su lectura y el relevamiento de fuentes realizado y planteando algunas hipótesis para encarar un estudio acerca de los orígenes del trotskismo argentino.

\section{Los origenes del trotskismo en Argentina}

Tras la diferenciación y posterior ruptura del dirigente ruso León Trotsky con la tendencia dirigida por José Stalin dentro del partido bolchevique soviético y la Internacional Comunista, situaciones similares transitaron muchos de los partidos comunistas en distintos países. La Oposición de Izquierda se desarrolló en la Unión Soviética desde los años 20 y en distintos países del mundo; a lo largo de la década del 30 enfrentó el proceso de burocratización de la URSS y el afianzamiento del estalinismo en la IC. Lo hizo primero como fracción de esta última, rompiendo con ella desde 1933 y, a partir de 1938, asumiendo el carácter de nueva organización, la IV Internacional. En la Argentina, esta ruptura se expresó en la aparición de algunos referentes y grupos que se reconocieron solidarios con las posiciones de León Trotsky y su organización. Las principales líneas políticas se desarrollaron a lo largo de la década de 1930 y se fueron rearticulando en los años siguientes. Haremos aquí un breve recorrido por estos grupos con el solo objetivo de presentar aquellos que resultan necesarios para seguir los principales debates a los que nos referiremos en este trabajo.

El primer grupo argentino se nucleó alrededor de un militante inglés, Roberto Guinney, y su hijo que coincidieron con el obrero español Camilo López -miembros del PC (RA), una ruptura de Partido Comunista, dirigida por José Penelón- vinculándose con las ideas de la Oposición de Izquierda Internacional a partir de 1929 y editando el primer número de su periódico La Verdad. Este grupo se acercó a dos intelectuales argentinos: Héctor Raurich y Antonio Gallo, el primero proveniente de una ruptura del Partido Comunista y el segundo vinculado al Partido Socialista.

Hacia 1935 Raurich y Gallo se unificaron con Pedro Milesi, dirigente 
municipal expulsado del PC y formaron la Liga Obrera Internacionalista, sección argentina, a la que adhirieron grupos de Córdoba y La Plata, mientras se consolidaban otros en Rosario. Hacia 1936 Liborio Justo, conocido como Quebracho, rompió con el PC declarando su adhesión a la Oposición de Izquierda.

Entre 1937 y 1938, implementando la táctica del "entrismo", a la que nos referiremos en este trabajo, se decidió la entrada de varios militantes en un ala izquierda del Partido Socialista que rompió con él formando el Partido Socialista Obrero, el PSO. Como resultado de esta experiencia, Mateo Fossa, dirigente del gremio de la madera proveniente del PS, adhirió al trotskismo. Él será quien se entreviste con León Trotsky en México en esos años. A fines de 1941 una serie de agrupamientos fundaron el Partido Obrero de la Revolución Socialista (PORS), que entró en declinación poco después.

Cuando el peronismo emerja, varios serán los grupos trotskistas. El Grupo Obrero Marxista (GOM) dirigido por Nahuel Moreno, surgió a partir de la elaboración de su primer documento en diciembre de 1943, editó desde fines de 1946 Frente Proletario y a fines de 1948 fundó el POR, Partido Obrero Revolucionario. El Grupo Cuarta Internacional (GCI) dirigido por Homero Cristalli, conocido como Posadas, publicó Voz Proletaria a partir de 1947. Octubre, fundado por Jorge Abelardo Ramos publicó una revista del mismo nombre entre 1945 y 1946. Por último, Frente Obrero, impulsado por Enrique Rivera y Aurelio Narvaja, publicó sólo dos números de su periódico en septiembre y octubre de 1945 y la Unión Obrera Revolucionaria (UOR) dirigida por Miguel Posse, publicó El Militante desde 1943.

Como dijimos, el tema de este trabajo ha sido objeto de poca atención por parte de los investigadores, particularmente en los ámbitos académicos. Dos son los estudios dedicados específicamente a la historia del trotskismo argentino. Uno de ellos es el trabajo de Osvaldo Coggiola (1985). El otro, coordinado por Ernesto González (1995), aborda la historia de la corriente fundada por Nahuel Moreno. Ambos autores son representantes de dos corrientes politicas pertenecientes al movimiento trotskista.

Otros trabajos que toman el tema lo hacen en función de objetivos más amplios. Norberto Galasso (1991) analiza la evolución de las corrientes politicas de izquierda en nuestro país en relación con la problemática de la liberación nacional y sus tareas; con este objetivo, dedica cinco capítulos al tema que nos interesa. Robert Alexander (1973, 1991) realiza dos extensos trabajos en los que la historia del trotskismo argentino ocupa un lugar, siendo sus objetivos, en un caso, reseñar la evolución de los partidos trotskistas en el mundo, en el otro, profundizar su desarrollo en América Latina; sus planteos son fundamentalmente 
descriptivos y no ofrecen una interpretación global. Pierre Broué, por su parte, dedica un número de su revista Cahiers León Trotsky al movimiento trotskista latinoamericano, en el cual incluye al argentino. Sin ser objeto específico de su investigación, y en el marco de un estudio sobre Milciades Peña y Silvio Frondizi, Horacio Tarcus (1996) realiza una valoración de los grupos trotskistas desde el punto de vista de su participación en los debates teóricos y políticos.

Por último, hemos publicado tres trabajos sobre el tema: uno de ellos enfoca los debates que entablaron los grupos en la década del 30 en torno a la consigna de "liberación nacional" y una política específica de construcción: el "entrismo" $(2001,2010)$. Otro trabajo desarrolla los análisis en relación a la definición del fenómeno peronista y el papel de la clase obrera y sus organizaciones (2002). Finalmente, otro estudio se propone analizar las politicas implementadas hacia la clase obrera y los sindicatos durante los primeros años de gobierno peronista (2004).

Además, encontramos artículos que toman aspectos parciales de la política de algunos de los grupos trotskistas a partir del estudio de uno de ellos, el "morenismo" y sus publicaciones, a los que nos referiremos más adelante.

Tras este panorama general de los estudios sobre el tema, nos detendremos en los análisis de los autores señalados acerca de los principales ejes que cruzan los primeros años del trotskismo en nuestro país.

\section{Sobre la década del 30}

Coggiola se propone un análisis de las posiciones políticas y teóricas de los primeros grupos trotskistas, particularmente la problemática de la "liberación nacional" y en consecuencia el carácter de la revolución en Argentina y sus tareas. Analiza fundamentalmente dos procesos por fuera de esta discusión teórico-política: el "entrismo" en el Partido Socialista Obrero, al que nos referiremos más adelante, y la relación de los grupos argentinos con la dirección de la IV Internacional.

Coggiola considera que los primeros quince años de historia de la corriente "lo marcarán de un modo singular, y alumbran muchas de sus vicisitudes posteriores" y se propone discernir por qué "los trotskistas llegan al viraje político del 4 de junio de 1943 (que prepara el gran viraje de Octubre de 1945: nacimiento del peronismo) de un modo muy distinto al del burocratizado PC y el esclerosado PS" (Coggiola, 1985:11). La etapa aparece definida entonces, explícitamente como clave para explicar la evolución posterior del movimiento. Efectivamente este punto de vista nos parece indicado para abordar el estudio de la historia del trotskismo en la Argentina: el análisis de la etapa de su formación nos 
permite echar luz sobre el desarrollo posterior, especialmente cuando se avecinaba un fenómeno político que marcaría las siguientes décadas de la historia nacional.

En cuanto al debate sobre la liberación nacional en Argentina, Coggiola lo define como "una verdadera novedad en el movimiento trotskista", pero poco más adelante lo califica como "una notable involución política, tanto más lamentable cuanto que prácticamente todas las energías de los trotskistas se dispersaron en este debate hasta 1945"; para volver a definirlo como "la lucha ideológica... más rica dentro del movimiento trotskista latinoamericano de los años 30" (Coggiola, 1985: 8-11).

El trabajo coordinado por Ernesto González estudia, como dijimos, el desarrollo de la corriente que se ha llamado "morenismo" a la que define desde el título del libro como "el trotskismo obrero e internacionalista en Argentina". Al referirse en las primeras páginas a los años previos a la aparición del GOM, plantea:

Aunque la historia de nuestra corriente comienza hacia 1943, resulta inevitable iniciar, aunque fuera de manera sintética, desde el surgimiento del trotskismo como tendencia diferenciada. Los fundadores del GOM no surgieron de la nada. Por lo tanto, comenzamos con lo que se podria considerar su "prehistoria": el desarrollo de la Oposición de Izquierda Internacional y la fundación de la Cuarta Internacional, y la actividad de los primeros grupos trotskistas en la Argentina. (González, 1995: 18)

Se hace aquí una primera definición en la evaluación de la etapa que estudiamos, que es considerada como la prehistoria del trotskismo argentino, lo cual implica no sólo una valoración de los primeros años del movimiento sino también de la importancia de la corriente morenista. Creemos que estos años son más que la "prehistoria" del trotskismo en Argentina, no sólo por lo que en ellos transcurre sino también en la medida en que su comprensión nos permite iluminar buena parte de la evolución posterior.

Indudablemente, el balance de esta etapa de la historia del trotskismo argentino, el análisis y la caracterización acerca del debate sobre la consigna de la liberación nacional, serán dos de los núcleos problemáticos que enfocaremos en nuestro estudio.

Norberto Galasso realiza un análisis de las posiciones políticas de los primeros trotskistas, resaltando, junto con el esfuerzo de explicación de la realidad, "la óptica alienada en los hechos externos", haciendo hincapié en el carácter "sectario" de sus análisis. Así, por ejemplo, buena parte de estos planteos "sectarios" (tales como no ver la posibilidad del 
surgimiento de movimientos antimperialistas conducidos por direcciones no socialistas) es atribuido por el autor a la "falta de inserción que aqueja a estos reducidos grupos de izquierda" (Galasso, 1991: 54).

Este balance nos introduce en otro nudo problemático: la relación con la realidad nacional de los grupos argentinos y la valoración de los vínculos con la corriente internacional a la que pertenecian, tema que se relaciona estrechamente con las posibilidades de inserción de los trotskistas en el movimiento obrero.

Por el contrario, Horacio Tarcus rescata la contribución de los trotskistas "a que los sectores más politizados del movimiento obrero no cayeran en la estrechez localista o en las ilusiones nacionalistas, difundiendo análisis politicos concebidos de acuerdo a una matriz mundialista. Sus periódicos informaban pues, mucho más que cualquier otra corriente política de la época, sobre los avatares de la revolución española, la situación de la clase obrera alemana, los preparativos para la guerra, la industrialización en la URSS o la política de la Internacional Comunista" (Tarcus, 1996: 86). Esta evaluación de los primeros años del movimiento trotskista argentino nos permite pensar en los aportes que efectivamente realizaron estos grupos tanto a la izquierda como al movimiento obrero. Y, aunque esto interese menos a Tarcus (lo que seguramente influye en su valoración positiva), estos elementos deben ponerse en diálogo con los esfuerzos por insertarse en la clase obrera, perspectiva central a considerar a la hora de evaluar la relevancia de un grupo de izquierda, más allá del éxito concreto de estos intentos.

Núcleos problemáticos, hipótesis exploratorias y lineas de investigación

Podemos delinear algunos núcleos problemáticos que nos permiten elaborar hipótesis exploratorias para abordarlos.

La valoración de la importancia de los primeros años del movimiento trotskista antes del surgimiento del peronismo nos enfrenta al menos a dos cuestiones, por un lado, el aporte que constituyeron las elaboraciones y polémicas teórico-políticas que desarrollaron los grupos en estos años; por otro lado, las posibilidades reales y las politicas que se dieron para insertarse en el movimiento obrero. Considerando su carácter de grupos iniciales, el esfuerzo desarrollado por los primeros trotskistas para delimitarse de las posiciones del resto de los partidos de izquierda ofrece una primera justificación a las energías empleadas en estas discusiones. El esclarecimiento de las propias posiciones y la diferenciación con el resto de los agrupamientos políticos existentes constituyó un momento necesario de la constitución de la propia corriente. Asimismo, la problemática debatida implicaba profundizar en un aspecto clave de la estrategia política de grupos que se consideraban revolucionarios: los 
sujetos y las tareas de la revolución en la Argentina. El referente político y teórico de estos grupos, León Trotsky, ha desarrollado extensamente estos temas, abordando la especificidad de los países atrasados en tanto se plantea en ellos la necesidad de considerar las tareas "democráticas" -entre las que se cuenta la liberación del país de la dominación imperialista- como un motor de la revolución socialista, estableciendo el rol hegemónico que debía asumir el proletariado en esta lucha y el papel del partido revolucionario. Creemos entonces que poner en diálogo las posiciones de los trotskistas argentinos con los análisis desarrollados por Trotsky es un punto de partida ineludible para una evaluación de estos debates (véase Trotsky, 2000 y 2007).

Así, la polémica en torno a la "liberación nacional" puso en primer plano la caracterización del país, su grado de dependencia del imperialismo, las posibilidades de las clases dominantes nativas de encabezar una lucha por la liberación de la dominación extranjera, la relación entre la lucha contra la burguesía nacional y el enfrentamiento con el imperialismo, el papel de las direcciones de la clase obrera en estos procesos, el rol de los propios trabajadores y su relación con los demás sectores y clases sociales.

La consideración de la importancia de estos debates se fortalece al ponerlos en relación con la lucha política que la Oposición de Izquierda Internacional entablaba en la Internacional Comunista; los trotskistas argentinos procuraban construirse como alternativa revolucionaria frente al proceso de "estalinización". Las discusiones alrededor de las concepciones políticas de la IC en sus diferentes virajes se proponian enfrentar las consecuencias políticas locales de estas líneas adoptadas por el PC argentino poniendo el acento en la necesidad del frente úni$\operatorname{co}^{3}$ y la crítica de la política de alianza con sectores de la burguesía. Se apuntaba entonces a cuestiones clave para el proletariado argentino.

Al mismo tiempo, este punto evidencia que, contrariamente a lo que plantean algunos autores, no se trataba de grupos ajenos a la vida nacional; realizaron, por el contrario, un esfuerzo notable por aplicar las herramientas teórico-políticas provistas por la corriente trotskista a nivel internacional, particularmente la "teoría de la revolución perma-

3. En respuesta a los virajes políticos implementados por la Internacional Comunista y su expresión en el PC argentino, los trotskistas discutieron contra la politica sectaria de los comunistas hacia las organizaciones sindicales de masas, planteando la necesidad del frente único de los trabajadores. Posteriormente, cuando la IC imponga a los partidos nacionales la politica de alianzas con sectores burgueses a través de los frentes populares, los trotskistas defenderán una posición de independencia de clase. 
nente" desarrollada por Trotsky (ver, por ejemplo, Gallo, 1933 y 1935; Quebracho, 1939a y b).

Los análisis realizados a comienzos de la década del 30 evidencian el objetivo de explicar los fenómenos políticos que transcurrian, comenzando por el golpe militar; sin embargo, cuando se operaban importantes cambios en la estructura económica y social del país, una primera revisión de los análisis de los trotskistas evidencia la falta de una adecuada actualización de la caracterización, particularmente de la relación del país con el imperialismo y el reforzamiento de los lazos de dependencia, así como el impacto de estas transformaciones en las relaciones entre las clases.

Este límite irá demostrando su importancia a lo largo de la década. Así, por ejemplo, la reafirmación del carácter capitalista del país les permitía enfrentar la concepción del tipo de revolución planteada por el PC para la Argentina y afirmar el carácter socialista de la misma y la hegemonía del proletariado. Pero mientras se sostenían los principios en torno a la necesidad de mantener la independencia de la clase obrera de los distintos sectores de la burguesía y el carácter socialista de la revolución, se agudizaba la confusión en torno al papel de las tareas democráticas ${ }^{4}$ y particularmente la necesidad de impulsar la lucha por la liberación nacional. El debate se intensificó alrededor de los planteos que otorgaban igual jerarquía a la lucha contra la burguesía nacional y contra el imperialismo, subestimando la particularidad de los países atrasados en los cuales la lucha por la liberación de la nación de la dominación imperialista otorga a la dinámica de la revolución características específicas. El afán por afirmar la diferenciación con los partidos de la izquierda que impulsaban alianzas con sectores de la burguesía, opacaba la visión de la perspectiva de la aparición de movimientos de masas que ofrecieran algún grado de resistencia al imperialismo y la reflexión en torno a la ubicación de los revolucionarios en estos procesos. Esta última debilidad se vuelve mucho más evidente a fines de la década, cuando el surgimiento de movimientos nacionalistas en América Latina planteaba la necesidad de un adecuado análisis de su carácter y de la política que los revolucionarios levantarian frente a ellos. Fue precisamente en estos años que Trotsky realizó sus elaboraciones acerca

\footnotetext{
4. Para los trotskistas, son tareas democráticas pendientes aquellas que, por la época histórica, la burguesía ya no está en condiciones de concluir quedando su resolución en manos del proletariado hegemonizando la alianza con campesinos y sectores populares. Son tareas democráticas la liberación de la nación de la dominación imperialista y la reforma agraria y también la defensa de libertades elementales de los trabajadores, como el derecho a la organización sindical.
} 
de estos fenómenos: frente al cardenismo, por ejemplo, como proceso latinoamericano, profundizó su categoría de "bonapartismo sui generis de izquierda" y definió la ubicación de los revolucionarios frente a estos regímenes a partir de la consideración de los aspectos de resistencia al imperialismo y manteniendo la independencia de las propias organizaciones frente a ellos. Estos análisis son tomados en forma fragmentada por Liborio Justo y su grupo, pero ignorados por el grupo liderado por Antonio Gallo. ${ }^{5}$

La problemática en torno a la inserción en el movimiento obrero involucra toda una serie de cuestiones que hacen a las condiciones objetivas y a las posibilidades subjetivas para vincularse a los trabajadores. La ligazón directa con el movimiento obrero resulta particularmente dificil para pequeños grupos iniciales. La implementación de tácticas políticas que permitan influir sobre sectores de trabajadores es una forma de sortear algunas de estas dificultades, a la vez que procuran fortalecer las propias organizaciones partidarias.

Hacia fines de la década, los trotskistas argentinos pusieron en práctica una táctica sugerida por Trotsky y su organización internacional para distintas secciones nacionales: el trabajo sobre las alas izquierdas que surgian al interior de los Partidos Socialistas. Esta táctica, también conocida como "giro francés", formaba parte de las políticas destinadas a impulsar la construcción de partidos revolucionarios a mediados de la década del 30; en el marco de los procesos de masas que se desarrollaron en esta época, Trotsky planteó la perspectiva del surgimiento de sectores que giraran a izquierda y se radicalizaran. Este proceso impactaría en los partidos reformistas, particularmente en los socialistas, en el que podrian surgir alas izquierdas con las que los revolucionarios pudieran confluir. La política de ingresar en estos partidos mientras estos sectores giraran a izquierda, tenía el objetivo de ganar elementos revolucionarios en ellos.

Los trotskistas argentinos implementaron esta táctica sobre la ruptura que se produjo en el PS, el Partido Socialista Obrero, el PSO. Esta escisión se dio en enero de 1937 y se trató de una ruptura "por izquierda", aunque no homogénea, que, en términos generales cuestionaba el abandono de una perspectiva revolucionaria por parte de la dirección del PS (véase Iñigo Carrera, 2006; De Lucía y Mereles, 2006; Martínez, 2008; Herrera, 2006). Fue precisamente en función de esta falta de homogeneidad y de una serie de criticas progresivas a la dirección de partido, además de un tipo de funcionamiento que permitía la integración de variados grupos en la organización, que los

5. Hemos realizado un análisis pormenorizado de estas posiciones en Rojo, 2010. 
trotskistas ensayaron el "entrismo" en el PSO. La discusión sobre la implementación de esta táctica generó diferencias, aunque la mayoría terminó ingresando; algunos lo hicieron primero, fundamentalmente sectores estudiantiles de La Plata y de Córdoba, que publicarán Frente Proletario; otros más tarde, entre ellos Antonio Gallo, quien inicialmente se opuso al ingreso, publicaron Izquierda y llegaron a controlar el centro del PSO en Liniers.

Es de utilidad retomar el balance de los principales estudiosos sobre este tema. Coggiola, aun resaltando las condiciones de "confusión teórica" en que se realizó esta experiencia, afirma que les "permitió sacar relativamente a los trotskistas de su aislamiento" y "ponerlos más en contacto con los problemas del movimiento obrero"; constatando que "al PC llegó a preocuparle esta actividad dirigida esencialmente contra la alianza estratégica con la burguesía materializada en la política del Frente Popular" (Coggiola, 1985: 24), y considera como un importante resultado de la experiencia la consolidación de Mateo Fossa como militante trotskista. Este último aspecto es igualmente destacado por Ernesto González. Efectivamente, la integración de Fossa, que fue uno de los dirigentes de la huelga de la madera de 1934 y cumplió un rol destacado en la de la construcción de 1935-1936, fue uno de los logros más relevantes de la década para los trotskistas argentinos, vinculado a esta experiencia "entrista".

Cuando se trata de hacer una evaluación de los esfuerzos de inserción de los trotskistas en la clase obrera y la realidad nacional, debe considerarse la puesta en práctica de esta política que implicó el intercambio con militantes de tradición en una organización de izquierda, el debate de posiciones y el involucramiento en torno a temas clave en la vida política del país, y el esfuerzo por ligar militantes de origen obrero a la organización.

Por otro lado, podemos plantear una segunda hipótesis sobre esta experiencia en relación con las posiciones con las que se llevó adelante la discusión política al interior del PSO. Sin estar en condiciones de realizar aún un análisis del conjunto de la política durante el entrismo, notamos que la problemática de la "liberación nacional" vuelve a plantearse ahora en debate con la izquierda del PS, evolucionando hasta la negación de esta lucha en los países atrasados. Así, sin evidenciar una ruptura con las posiciones establecidas por sus antecesores, las publicaciones editadas durante el entrismo muestran un salto hacia una visión más mecanicista y esquemática. Si bien debemos evaluarlas considerando la lucha que estos militantes entablaban al interior del PSO -en función de la cual se esforzaban por asentar una politica de independencia de clase frente a una dirección que se hacía cada vez más "frente-populista"-, podemos arriesgar que, con un análisis poco 
riguroso de la estructura económica y social del país, con las debilidades de las elaboraciones previas y con la presión de la militancia dentro de un partido reformista, la experiencia del entrismo en el PSO no se asentó en los aspectos más fuertes de las anteriores elaboraciones sino que profundizó los más débiles, agudizando la confusión, particularmente en torno a la utilización de la consigna de liberación nacional.

Ambos aspectos del balance reconocen como telón de fondo una serie de condiciones objetivas y subjetivas que constituyen una hipótesis central a la hora de explicar las dificultades de inserción de los trotskistas en el movimiento obrero y de hallar una síntesis adecuada de las diferencias políticas. Debemos considerar una combinación de problemas políticos comparables, en muchos casos, con los que sufrian otras secciones de la Oposición de Izquierda y la IV Internacional. Las condiciones objetivas instalaron a los primeros trotskistas en una época de abierto enfrentamiento entre procesos revolucionarios agudos y fenómenos de reacción y contrarrevolución. Estos tuvieron su expresión en la Argentina, en el transcurso de la "década infame" y favorecieron la situación de aislamiento en el grupo, sometido, como la mayor parte de la izquierda, al control estatal de sus actividades. A esto debe agregarse la persecución que sufrian los trotskistas por parte del estalinismo: la dirección del Partido Comunista no sólo ejercía un método de control burocrático al interior del partido, sino que, particularmente con la consolidación de la dirección estalinista a nivel internacional, impuso una persecución en todos los ámbitos de discusión política o de actuación sindical en que los militantes trotskistas pudieran coincidir con los comunistas. $\mathrm{Y}$ era en este contexto donde los trotskistas debían delimitarse teórica y políticamente del estalinismo. En este marco, las características que tendian al sectarismo, al mecanicismo de las posiciones o a la prevalencia de los personalismos, pudieron verse reforzadas.

\section{E1 surgimiento del peronismo}

\section{Los trotskistas y el carácter del peronismo}

En la introducción de este trabajo reseñamos los distintos grupos argentinos presentes a comienzos de la década del 40. Aquí elegimos concentrarnos en el Grupo Obrero Marxista (GOM) y el Grupo Cuarta Internacional (GCI). La elección de estos grupos se debe tanto a su permanencia dentro del movimiento trotskista como a la influencia política que ejercieron: el grupo de Moreno dio origen a una de las corrientes de mayor peso en la Argentina; el de Posadas se constituyó en una tendencia importante del trotskismo latinoamericano en la década de 1950.

Tomando ahora como ejes la caracterización del nuevo fenómeno 
político y la inserción del trotskismo en el movimiento obrero durante los primeros años peronistas, consideraremos, como en el apartado anterior, los planteos generales de la bibliografia sobre el tema y delinearemos algunos núcleos problemáticos e hipótesis exploratorias.

El trabajo de Coggiola estudia las posiciones de los cinco grupos reseñados más arriba. Los análisis más extensos los dedica al GOM, desarrollando una interpretación manifiestamente contraria a las posiciones de la corriente "morenista": "En materia de entroncar con el antiperonismo liso y llano, ningún grupo trotskista superó al GOM, liderado por Nahuel Moreno" (Coggiola, 1985: 98-99). En cuanto al GCI, "no cae en el sectarismo atroz del GOM o la UOR en relación a las movilizaciones peronistas, pero sí en la perogrullada: los obreros obrarian 'llevados por su instinto anticapitalista'. El peronismo sería la 'expresión instintiva' de los obreros (y conciente de la burguesia)" (Coggiola, 1985: 102). Como balance general, para este autor, "las posiciones de los diversos grupos trotskistas en el momento del surgimiento del peronismo no se diferenciaban claramente de las dos corrientes fundamentales en que se había dividido la sociedad argentina: peronismo y antiperonismo." (Coggiola, 1985: 103).

$\mathrm{Si}$, como dijimos, los análisis de Coggiola están teñidos por su contraposición a los planteos de la corriente morenista, González parte de su ubicación como integrante y protagonista de esta corriente. Reconoce la dificultad del GOM para analizar correctamente el fenómeno del 17 de octubre: "En su artículo «¿'Movilización antiimperialista o movilización clasista?» Moreno, polemizando con otros dos grupos trotskistas, la UOR y el GCI, decía cosas de las que después él mismo y el partido se autocriticaron por unilaterales" (González, 1995: 120)

Se refiere al trabajo en el que Moreno caracterizaba a la movilización del 17 de octubre como "lucha de camarillas", en la que "el proletariado atrasado salió a defender el orden burgués contra la propia burguesía" y que "en ningún momento el proletariado dejó de ser utilizado." Sin embargo, González rescata que

el GOM, a diferencia de las otras corrientes, fue adonde estaban los obreros peronistas, y educó a sus militantes y simpatizantes en que el respeto a la voluntad de la base era una cuestión decisiva de la democracia obrera, tan importante como su independencia de los patrones y el Estado. (González, 1995: 119)

Por su parte, las conclusiones de Norberto Galasso están impregnadas por sus valoraciones positivas acerca del fenómeno peronista, definiendo la ubicación de los grupos de uno u otro lado "de la barricada". Esto se advierte claramente en su balance general cuando opina que tanto 
al GOM como al GCI "se les escurre una clase trabajadora que realiza una experiencia valiosísima, que no se engaña en el 45 pues opta por el bando históricamente más progresivo y lleva a cabo importantísimas conquistas... en un proceso de revolución nacional que debilita profundamente el enemigo principal"(Galasso, 1991: 207).

Horacio Tarcus tiene especial interés en los trabajos teóricos del GOM, tales como las "Tesis agrarias" o las "Tesis industriales". Acerca de su argumentación sobre el peronismo destaca que fue

mucho más sofisticada y sutil que la de socialistas y comunistas, pero llegaba a muchas conclusiones politicas similares a las de éstos y corría muchos de sus riesgos políticos... Pero cierta ductilidad política que siempre caracterizó a esta corriente le permitió muchas veces jugar en la práctica un margen de maniobra que no siempre toleraba el discurso. Es así que los militantes trotskistas del GOM persistirán en su obstinado trabajo sindical en los años del peronismo, aún en los gremios integrados en la CGT. (Tarcus; 1996: 108)

Asemejar las diferencias políticas entre los dos principales grupos trotskistas a las líneas de enfrentamiento peronismo-antiperonismo, como concluye Coggiola, implica simplificar extremadamente las posiciones y divergencias entre ellos, además de opacar la visión de las contradicciones que al interior de los mismos grupos se dieron entre sus líneas y sus prácticas políticas.

El GOM caracterizó al peronismo como "agente" inglés en tanto expresión de los intereses del sector más fuerte de la burguesía argentina, los terratenientes. Este sector ofrecía cierta resistencia frente al avance de la influencia del imperialismo norteamericano que afectaria a la economía en su conjunto, tradicionalmente ligada al capital británico; en este sentido forzó la unidad de las clases explotadoras y la colaboración con el imperialismo inglés. Así, el GOM subestimaba los rasgos nacionalistas del régimen, que implicaron la creación de condiciones de relativa autonomía del imperialismo en la etapa (desarrollo de la industria, política de nacionalizaciones, fortalecimiento del mercado interno, etc.). Por otro lado, al analizar las características de la clase obrera, para el GOM resultaban centrales tres elementos: la situación de "reflujo" de los trabajadores, el rol jugado por las direcciones "reformistas" del movimiento obrero y la utilización que el peronismo hizo del proletariado, en un marco general de prosperidad económica. Estas condiciones permitieron que el proletariado haya servido al plan demagógico del gobierno y fuera desviado de los métodos de lucha revolucionarios y de sus objetivos de clase, sin constituirse en una fuerza capaz de determi- 
nar cambio político alguno. En este marco, el proceso de estatización de los sindicatos respondía a estos objetivos y obedecía a las necesidades del conjunto de la burguesía y del imperialismo de reforzar el control sobre la clase obrera. Así, el GOM parte del error de absolutizar el estado de desmovilización del movimiento obrero (sin ver las tendencias que expresaban por ejemplo, la conformación del Partido Laborista) y no advierte que la "utilización" del proletariado como base de apoyo social del peronismo se basaba en la fortaleza objetiva del proletariado como clase, que explica en buena medida el logro de importantes conquistas. ${ }^{6}$ Hacia 1948-1949 el partido introdujo modificaciones en esta visión de la situación de una clase obrera pasiva y desmovilizada, pero no todavía en su caracterización global del fenómeno peronista.

El GCI definió al gobierno de Perón como representante de la "burguesía industrial nacionalista" y consideraba que ésta, en función de sus intereses de desarrollo de la industria y el mercado interno, se oponía al imperialismo y a la oligarquía terrateniente. Para el GCI, esta burguesía nacionalista se sirvió de la lucha entre los imperialismos norteamericano y británico, para disputarle a ambos parte de la plusvalia que extraían del proletariado. Definía la relación del régimen peronista con la clase obrera a partir de la necesidad de la burguesía industrial de obtener una base social de apoyo para llevar adelante su política industrialista y "negociar" en mejores términos su relación con el imperialismo. Desde el punto de vista del apoyo brindado por el proletariado al peronismo, para el GCI los trabajadores respaldaban a Perón en función de sus propios "intereses revolucionarios", intereses que la burguesía utilizó en su beneficio pero que, al mismo tiempo, la obligaron a hacer concesiones a las masas. Esta visión del GCI de la burguesía industrial argentina encerraba una sobrevaloración de su "independencia" y de la profundidad de su enfrentamiento con el imperialismo, y lo llevará, en términos políticos, a una "adaptación" al peronismo como representante político de esa burguesía y como dirección "real" de la clase obrera. Aunque reparó tanto en los rasgos nacionalistas del peronismo como en su necesidad de constituir a la clase obrera en base social de apoyo y el rol de las concesiones en este proceso, al no profundizar en los mecanismos de cooptación de la clase y burocratización y estatización de sus organizaciones, este grupo hizo hincapié en la "experiencia" que los trabajadores hacían con el peronismo adaptándose al estado de conciencia de la clase obrera en esta etapa. El acento puesto en la

6. No podemos desarrollar aquí una visión del peronismo, en un trabajo anterior hemos desarrollado nuestro análisis sobre este fenómeno político incorporando la categoría de "bonapartismo sui generis" planteada por Trotsky y retomada por historiadores como Ernesto González (Rojo, 2002). 
"experiencia" que la clase obrera estaba realizando no le permitía ver el proceso que impedía que esa experiencia cristalizara en organizaciones independientes.

Si bien la caracterización del GOM resulta parcial e incluía elementos "sectarios", para tomar el término utilizado por Galasso, en relación al carácter del fenómeno peronista, profundiza en el proceso de burocratización, estatización de las organizaciones sindicales y la cooptación de amplios sectores del movimiento obrero. Asi, el GOM pudo alertar sobre otro proceso que se estaba produciendo y que tendría profundas consecuencias para la clase obrera: la burocratización y estatización de los sindicatos. Asimilar esta visión a una variante del "antiperonismo" creemos que obstaculiza un adecuado análisis de los mecanismos que esta corriente intentará implementar para ligarse a sectores del movimiento obrero, apelando a tendencias profundas en la clase que apuntaban al protagonismo de las bases, aún a contramano de sus análisis más generales. Más adelante retomaremos este punto.

En cuanto al GCI, éste sobreestima los aspectos "progresivos" del peronismo al evaluarlo como una "oportunidad" para profundizar la experiencia de la clase obrera. Sin embargo, sus argumentos distan mucho de las corrientes politicas que adhieren al peronismo en tanto sostiene la denuncia del fenómeno como movimiento burgués y las implicancias de este carácter. En cualquier caso, los mecanismos por los cuales, el posadismo desarrolla en el corto plazo una dinámica política de adaptación al peronismo merecen un análisis más profundo.

Estas consideraciones discuten también con los planteos de Galasso que evalúa la ubicación de los trotskistas frente al peronismo en tanto no se integraron en este movimiento al que considera progresivo, calificándolos de "sectarios" de conjunto. No le interesa, en consecuencia, reparar en las diferencias entre los grupos trotskistas ni preguntarse sobre las políticas que desarrollaron hacia la clase obrera, en la medida en que los ubica sin más en la "barricada" incorrecta.

Por su parte, como planteamos, González reconoce la dificultad para analizar el peronismo pero rescata el esfuerzo de vinculación con la clase obrera. Creemos que éste es precisamente un punto a profundizar. Qué relación se estableció entre los análisis teórico-políticos del fenómeno peronista y las politicas desarrolladas para ligarse a una clase obrera mayoritariamente peronista es un interrogante válido para encarar el estudio de la inserción de los trotskistas entre los trabajadores y los limites que encontraron.

Desde un punto de vista, Tarcus nos hace pensar en este aspecto al señalar la contradicción que plantea que la caracterización política del morenismo sobre el peronismo no le impidió dirigirse a los trabajadores adjudicando esto a la "ductilidad política que siempre caracterizó 
a esta corriente"; consideramos que este aspecto amerita una mayor reflexión.

Finalmente, los artículos de Barton y Castelo intentan explicar la "construcción de partido" del morenismo adjudicando sus deficiencias a una concepción política que "subdesarrolla" la función intelectual dirigente del partido, cediendo a la espontaneidad de las masas. No haremos aquí un análisis de la metodología aplicada por los autores para arribar a las conclusiones mencionadas, pero nos parece que se trata de fundamentar una interpretación que pretende encontrar un problema "genético" en el morenismo, una "idea" que guiaría toda su construcción, que lo llevaría a devaluar el rol intelectual del partido. Aunque, como dijimos, nos parece fundamental encontrar la relación entre las concepciones teórico-políticas y las prácticas de una corriente que se propone construirse en la clase obrera, creemos que tenemos que alejarnos del método a-histórico de buscar relaciones automáticas entre ambas sin ponerlas en diálogo con las condiciones de militancia, los objetivos propuestos, los obstáculos que se encontraron y los logros obtenidos.

\section{Los trotskistas y su politica hacia la clase obrera}

Afianzado el peronismo en el poder y consolidada su posición como dirección del movimiento obrero, el trabajo de los militantes de izquierda sobre la clase obrera se tornó extremadamente dificil. La bibliografía acerca del peronismo y su papel en el sindicalismo es muy amplia y encontramos múltiples elementos para explicar el proceso de control que el peronismo ejerció sobre los sindicatos, el enorme salto en la burocratización de las organizaciones obreras y la persecución a las corrientes de la izquierda; esto se combinó con un proceso de adhesión política de los trabajadores al peronismo sustentado en inéditas conquistas materiales para las masas, así como en la profusa difusión de la ideología de armonía de clases en explícita condena a la prédica tradicional de la izquierda.

Frente a un fenómeno nacionalista de las dimensiones del peronismo, el objetivo de desplegar una politica revolucionaria entre los trabajadores creemos que extremó las contradicciones contenidas en las caracterizaciones politicas de la situación, el gobierno y la clase obrera. Al mismo tiempo, seguramente, una mayor justeza y precisión en los análisis del proceso que presenciaban hubiera puesto a los trotskistas en mejores condiciones de establecer un diálogo con sectores de trabajadores y avanzar en la consolidación de grupos revolucionarios. Plantearemos algunos elementos que ayuden a sustentar estas hipótesis.

La inserción de los trotskistas, acorde con las condiciones que des- 
cribimos brevemente más arriba, fue débil. Sin embargo, las características que asumia la militancia de izquierda en la época permitian a los activistas insertos en una estructura obrera ejercer una influencia que superaba frecuentemente la cantidad de militantes efectivos. Así, sin ser nuestro objetivo en este trabajo realizar un análisis de la inserción obrera de los trotskistas, un recorrido por las fuentes permite advertir cómo la actividad de un militante en una fábrica destacada podía multiplicar la influencia de su agrupación política en la rama o el sindicato, a través de variadas tácticas de intervención.

El GOM logró implantación en establecimientos fabriles de la rama metalúrgica como Siam y Tamet o la Fábrica Militar de Acero y en fábricas como Ferrum y Colgate. Las principales posiciones sindicales del GCI se consolidaron en los gremios textiles y metalúrgicos, en fábricas como Alpargatas y Siam. Así, ambos grupos otorgaron una importancia central a insertarse en áreas claves de la economia y en estructuras de importancia sindical estratégica.

En cuanto a sus avances entre los trabajadores, Coggiola plantea en relación al GOM que "pudo progresar durante este periodo pues, si bien planteaba la lucha contra la CGT, no se negaba a militar dentro de los sindicatos 'creados por Perón." Para este autor, la política del GCI se limitaba a "'ayudar a las masas', 'comprender a los obreros', toda la lucha politica del GCI se diluía en medio de esas declaraciones de intención” (Coggiola, 1985:107).

Ambos grupos, siguiendo los lineamientos de la corriente trotskista internacional, se planteaban la necesidad de trabajar en los sindicatos para insertarse en la clase obrera y lo hacian guiados por una politica general que apuntaba a la lucha por la democracia sindical y la independencia de los sindicatos del Estado (Trotsky, 2000 y 2010).

En este marco, el GOM planteaba una politica de organización dirigida a los trabajadores. Partiendo de la denuncia de las traiciones de las direcciones y los reclamos sindicales insatisfechos, impulsó tácticas que iban desde el llamado a formar "comisiones internas revolucionarias", "sindicatos revolucionarios", hasta la consigna más ampliamente agitada: la formación de "oposiciones sindicales", "con todo obrero honrado y luchador que quiera que su sindicato sea libre, democrático y anticapitalista".

El GCI desarrolló fundamentalmente una política de propaganda de su programa y de exigencia a las direcciones sindicales estructurada alrededor del llamado "Programa de Transición", el programa de la Cuarta Internacional elaborado por Trotsky en 1938. Este era "ofrecido" por el GCI para la discusión a los trabajadores en las fábricas. En función de este planteo es que se hacía un llamado a la formación de "agrupamientos", "núcleos" o "comisiones" que en las fábricas y lugares 
de trabajo discutan el programa. Esta política se acompañaba en cada caso con la exigencia a las direcciones (comisiones internas, sindicatos o CGT) para que impulse la lucha en situaciones concretas o el llamado al proletariado para que "imponga" este programa a esas direcciones.

El GOM tuvo un crecimiento mayor en este período; a pesar de los límites de su caracterización del peronismo como régimen, logró cierta inserción en la clase y acercar algunos cuadros obreros. A modo de hipótesis a profundizar, podemos pensar en el sentido de la crítica que esboza Andrés Delgado, como miembro de la organización: "habiamos superado nuestro propagandismo, pero nos emborrachábamos de sindicalismo" (Coggiola, 1985: 106). Si bien su visión del carácter del peronismo les obstaculizaba, con toda seguridad, el diálogo con trabajadores peronistas, las tácticas específicas en cada empresa les permitió ligarse con obreros que sí veían la necesidad de fortalecer y radicalizar el trabajo sindical para conseguir o mantener las conquistas laborales, e incluso transformar las organizaciones en herramientas de lucha más eficaces. Probablemente una "separación" entre la politica general, que podemos definir de "sectaria" en relación al peronismo -y hacia la clase obrera en tanto ésta consideraba al peronismo su gobierno y a la CGT y los sindicatos como sus organizaciones-, y las tácticas específicas en los establecimientos en los que se insertaba, le permitia al GOM ligarse con elementos de la clase que se oponían a los delegados o comisiones internas o advertian las "traiciones" de la CGT; pero no necesariamente comprendian a fondo el carácter de clase del gobierno peronista y su movimiento, las tareas de la revolución o la necesidad de la militancia en un partido revolucionario. Al mismo tiempo, seguramente, una comprensión más ajustada del proceso de burocratización de las organizaciones sindicales le permitió al GOM apuntar su construcción hacia las tendencias más vitales de la clase obrera que desarrollaran experiencias de democracia de base desde las comisiones internas y los cuerpos de delegados. De conjunto, esta política pudo facilitar su crecimiento circunstancial y afianzarse como experiencia política -fundando una nueva agrupación a fines de 1948, el POR-, pero no fortalecerse en el largo plazo en algún sector de la clase para transformarse en una alternativa hacia fines del gobierno peronista, cuando el descontento obrero se profundizó. La comprensión de las debilidades de sus análisis y de sus políticas llevará al POR a modificar radicalmente su política a fines del gobierno peronista y ensayar, posteriormente, una experiencia de "entrismo" en el peronismo.

En el caso del GCI, su visión de una clase obrera que espontánea e instintivamente se orientaba hacia la revolución, y su apuesta al surgimiento de una vanguardia revolucionaria, le imprimió a su política un sesgo "propagandista" que se adjudicaba el papel de "consejero", de 
"aclarar" con el programa del trotskismo a la vanguardia que surgía y hacía su experiencia. Si bien tuvieron una política de dirigirse hacia los distintos gremios, el eje no estaba puesto en la organización sino en la apelación a la discusión del programa trotskista, en la exigencia a la central sindical y a los sindicatos y en el llamado a imponer este programa a las direcciones. Podemos ver esta devaluación de una política de organización independiente de los trabajadores en estrecha relación con el débil análisis del proceso de burocratización y estatización de las organizaciones sindicales y su visión más general del peronismo como expresión de un sector nacionalista de la burguesía. Podemos arriesgar que esta política no podía tener otro destino que el de diluir al grupo en un movimiento obrero que estaba lejos de romper con su dirección peronista.

Sintetizando, nos parece que indagar acerca de la relación entre las líneas políticas de los partidos de izquierda y su implementación en la inserción en la clase obrera permite iluminar el balance de los logros obtenidos en el mediano y en el largo plazo. Una concepción de tipo "sindicalista", que separaba los análisis teórico-políticos de las prácticas políticas, pudo permitirle al morenismo una construcción en el corto plazo -en el marco de las condiciones objetivas a las que nos referimos-, pero obstaculizaron la construcción de una herramienta política revolucionaria para los trabajadores. Asimismo, el posadismo, que no definía claramente el alcance de los mecanismos con los que la clase dominante burocratizaba y estatizaba las organizaciones de los trabajadores y los efectos de este proceso sobre la subjetividad obrera, perderá de vista en el mediano plazo la necesidad de construir alternativas políticas de los trabajadores independientes del Estado y la dirigencia sindical para ceder a las tendencias que esperaba que cristalizaran en la clase obrera.

$$
* * *
$$

Creemos que un balance crítico de los orígenes del trotskismo en nuestro país permite valorar los aportes de esta corriente. Por un lado, hemos mostrado el desarrollo de un debate teórico-político que implicó la reflexión sobre las tareas de la revolución en la Argentina y la confrontación con los principales referentes de la izquierda nacional, demostrando no sólo el esfuerzo por responder a problemas políticos centrales sino también por insertarse en el medio nacional, manteniendo al mismo tiempo los vínculos con sus referentes internacionales. Esta constatación responde a la crítica -y en buena medida al prejuicio- sobre la falta de ligazón del trotskismo con el medio nacional en el que actuaban. Por otro lado, también es posible responder al cuestiona- 
miento acerca del desinterés por la relación con los trabajadores y los problemas de construcción política; los trotskistas han ensayado formas de intervención en fenómenos políticos que les abrian posibilidades de debate y construcción.

En las condiciones objetivas que hemos señalado en este trabajo, y con los límites que analizamos, estos elementos pusieron las bases de agrupaciones politicas que asumirán una presencia permanente en la realidad nacional. Aún así, creemos que son precisamente algunos de sus límites los que les impedirán a los trotskistas allanar el camino a la construcción de organizaciones revolucionarias de peso tras el fenómeno político de magnitud que constituyó el peronismo.

Como hemos desarrollado, esto se debió a la combinación de una serie de elementos como las dificultades en la aplicación de herramientas teóricas y políticas provistas por la corriente internacional a la que pertenecian, los problemas para caracterizar un fenómeno que involucraba a los trabajadores y a sus organizaciones y diseñar por tanto una politica que los vinculara en forma revolucionaria -tales eran sus objetivos políticos- con esos obreros que adherian al peronismo. Aún así, los lazos que pudieron forjar les permitieron, en términos generales, lograr una notable permanencia como corrientes políticas, aunque no constituirse como alternativa de dirección para los trabajadores argentinos.

Por supuesto no hemos desarrollado aquí una multitud de aspectos ligados con la reflexión de procesos internacionales, la caracterización de distintos fenómenos de la vida nacional y de la clase obrera, la respuesta a cuestiones teóricas y politicas de diversa índole, que pueden rastrearse en las fuentes disponibles sobre esta etapa. Hemos desarrollado sólo algunos ejemplos que consideramos centrales y que nos permitian dialogar con ciertos planteos de la producción historiográfica existente.

Una historia del trotskismo argentino en todas sus variantes está aún por hacerse; como quedó claro, la producción en torno a este tema es escasa. Como obras generales sólo contamos con los trabajos de Coggiola y el estudio coordinado por González que comparten, a la vez que un interés histórico, un objetivo político. Si bien las razones de esta ausencia son seguramente complejas, no puede soslayarse el aislamiento sufrido por esta corriente política a nivel mundial tras la consolidación de la burocracia soviética. La falsificación construida por el estalinismo en torno a la figura de León Trotsky y su corriente tras el objetivo de eliminarla como alternativa politica, fines sin duda funcionales a los intereses de las clases dominantes, ha impactado también sobre la producción historiográfica y los análisis políticos. Encarar el estudio desde una perspectiva marxista de la historia del trotskismo es una tarea que, desde nuestro punto de vista, implica no sólo hacer justicia con una de las tradiciones políticas revolucionarias de mayor 
peso en la historia del movimiento obrero internacional, sino también recuperar junto con ellas herramientas fundamentales para la lucha de los trabajadores hoy día; tal es, para nosotros un rol clave de la intelectualidad y esperamos poder aportar a ello.

\section{Bibliografia}

Alexander, Robert (1973), Trotskyism in Latin America, California: Hoover Institution Press, Stanford University.

- (1991), International Trotskyism. 1929-1985. A documented analysis of the movement, Duke University Press.

Barton, Alejandro (2002), "Para un análisis de la estrategia morenista sobre la construcción del partido. Apuntes en torno al primer documento del GOM”, Razón y Revolución, ${ }^{\circ} 9$.

Broué, Pierre (1982), "El movimiento trotskista en América Latina en 1940", Cahiers León Trotsky, $\mathrm{n}^{\circ} 11$.

Castelo, Fernando (2002), "Clase y partido bajo el peronismo. El GOM (19461948)", Razón y Revolución, $\mathrm{n}^{\circ} 9$.

Coggiola, Osvaldo (1985), El trotskismo en la Argentina (1929-1960), Buenos Aires: Centro Editor de América Latina.

De Lucía, Daniel Omar y Elizabeth Mereles (2006), "Relaciones curiosas: trotskismo y socialdemocracia (1929-1956)", en Hugo E. Biagnini y Arturo A. Roig, El pensamiento alternativo en la Argentina del siglo XX, tomo II: Obrerismo, vanguardia y justicia social (1930-1960), Buenos Aires: Biblos.

Galasso, Norberto (1991), Liberación nacional, socialismo y clase trabajadora, Buenos Aires: Ed. Ayacucho.

Gallo, Antonio (1933), Sobre el movimiento de septiembre. Ensayo de interpretación marxista, Buenos Aires: Claridad

- (1935), ¿Adónde va la Argentina? ¿Frente popular o lucha por el socialismo?, Rosario: Ediciones Mariátegui

González, Ernesto (coord.) (1995), El trotskismo obrero e internacionalista en la Argentina, Buenos Aires: Editorial Antídoto.

Herrera, Carlos M. (2006), "Corrientes de izquierda en el socialismo argentino, 1932-1955”, Nuevo Topo. Revista de historia y pensamiento crítico, I, 2, abril-mayo, pp. 127-153.

Iñigo Carrera, Nicolás (2006), "Alternativas revolucionarias en los 30: la Alianza Obrera Spartacus y el PSO", en Hugo E. Biagnini y Arturo A. Roig, El pensamiento alternativo en la Argentina del siglo XX, tomo II: Obrerismo, vanguardia y justicia social (1930-1960), Buenos Aires: Biblos.

Martinez, Ilana (2008), "Un acercamiento a la izquierda del Partido Socialista a través de su prensa periódica. La revista Izquierda. Crítica y Acción Socialista, 1934-1935”, Papeles de trabajo, revista electrónica del Instituto de Altos Estudios Sociales de la UNGS, año 2, $\mathrm{n}^{\circ}$ 3, Buenos Aires, junio 
Quebracho (1939a), Por el socialismo revolucionario y por la Cuarta Internacional, Buenos Aires: Ediciones Acción Obrera

- (1939b), La revolución mundial y la traición stalinista, Buenos Aires: Ediciones Acción Obrera.

Rojo, Alicia (2001), "Los trotskistas argentinos frente a la Segunda Guerra Mundial", Cuadernos del CEIP, Buenos Aires: Ediciones CEIP.

- (2002), "El trotskismo argentino y los orígenes del peronismo", Cuadernos del CEIP, Buenos Aires: Ediciones CEIP.

- (2004), "El trotskismo argentino y la clase obrera durante el primer gobierno peronista", II Congreso de Sociología - VI Jornadas de Sociologia de la UBA.

- (2010), Los orígenes del trotskismo argentino, una aproximación a sus elaboraciones teórico-políticas, Boletín Electrónico del CEIP León Trotsky, $\mathrm{n}^{\circ} 13$, www.ceip.org.ar.

Tarcus, Horacio (1996), El marxismo olvidado en la Argentina. Silvio Frondizi y Milcíades Peña, Buenos Aires: Ediciones El Cielo por Asalto.

Trotsky, León (2000), La teoria de la revolución permanente, Buenos Aires: Ediciones CEIP

- (2007), Escritos Latinoamericanos, Buenos Aires: Ediciones CEIP.

- (2010), Los sindicatos y las tareas de los revolucionarios, Buenos Aires: Ediciones CEIP.

$$
* * *
$$

Resumen: En este trabajo nos proponemos abordar los orígenes del trotskismo argentino planteando una serie de núcleos problemáticos que surgen del debate con los estudios existentes sobre el tema y el análisis de un conjunto de fuentes de los principales grupos de esta corriente. Recorremos algunos de los debates teóricos y políticos más importantes que se llevaron adelante a lo largo de la década del 30 y los primeros años 40, especialmente alrededor de la cuestión de la "liberación nacional". Nos detenemos particularmente en los análisis desarrollados por los grupos trotskistas frente al surgimiento del peronismo y las políticas diseñadas para vincularse con la clase obrera durante estos años, enfocándonos en dos de las agrupaciones que se conocerán como el "morenismo" y el "posadismo".

Palabras clave: trotskismo argentino - liberación nacional - peronismo - morenismo - posadismo

Abstract: In this paper we will address the origins of Argentine Trotskyism, discussing a number of core problems arising from existing studies on the subject and from the study of a set of sources produced by the main groups belonging to this tendency. We will deal with some of the theoretical debates and political issues raised by this current during the 30's and early 40's, especially around the issue of "national liberation". We will particularly deal with their analyses of the rise of Peronism and with their attempts to link with the working class over 
the years, focusing on two groups known as "Morenoism" and "Posadism", after the pseudonyms of their main leaders, Nahuel Moreno (Hugo Bressano) and J. Posadas (Homero Cristali).

Keywords: Argentine Trotskyism - national liberation - Peronism - Morenoism - Posadism

Recepción: 15 de julio de 2012 - Aprobación: 8 de agosto de 2012 